\title{
INTERNA KONTROLA I KOMPONENTE INTERNE KONTROLE
}

\section{Rezime}

Usled veoma dinamičnih promena na tržištima, pogotovo na tržištima kapitala,vlasnicima kapitala i investitorima potrebno je pouzdano i nezavisno mišljenje o finansijskim izveštajima preduzeća koja su predmet njihovog interesovanja. U uslovima koje karakteriše velika unificiranost heterogenih finansijskih izveštaja, menadžment preduzeća traga za načinom boljeg uspostavljanja kontrole preduzeća, što predstavlja dug i kontinuiran proces. Punu podršku u tome pruža mu interna kontrola i interna revizija poslovanja preduzeća.

Ključne reči: menadžment, interna kontrola, interna revizija.

\section{UVOD}

Menadžment savremenog društva suočen je sa potrebom donošenja poslovnih odluka u vezi sa ostvarenjem poslovnih ciljeva.Sistem internog nadzora koji uključuje sve mere pažnje usmerene na sprečavanje grešaka prekomernih troškova i prevare,proverava i obezbeđuje pouzdanost informacija.Ključni zadatak internog nadzora jeste da kontroliše sve delove preduzeća da li dosledno redukuju poslovnu politiku usvojenu na početku poslovnog perioda,kao i da o tome podnose informaciju menadžmentu privrednog društva.Za pojačano interesovanje za uspostavljanje internog nadzora razlog više su i prisustvo nelojalne konkurencije, povećane konkurencije i urušavanje poslovnog morala.

\section{INTERNA KONTROLA}

Osnovni i najvažniji oblik kontrole u preduzeću,s obzirom na njen karakter,predstavlja interna kontrola.Za interne kontrole su zainteresovani skoro svi,od eksternih revizora do uprave,borda direktora,velikih kompanija,pa sve do države.Sistem interne kontrole ${ }^{7}$ podrazumeva sve politike i postupke koje je usvojila uprava nekog preduzeća kako bi joj pomogli u postizanju cilja uprave vezanog za obezbeđenje: poslovanja,politike,uprave,zaštite sredstava,sprečavanje prevare i greške,tačnost i kompetnost računovodstenih isprava i blagovremenu pripremu pouzdanih finansijskih informacija.

Za internu kontrolu odgovorni su svi u organizaciji:menadžment,upravni odbor,interni revizori i ostalo osoblje.Najodgovorniji je izvršni direktor koji treba da preuzme nad sistemom interne kontrole,odnosno da vodi i daje direktive višim menadžmentima.Upravni odbor čija je glavna obaveza da obezbedi rukovođenje,davanje direktive i nadgledanje.Interna kontrola se može definisati kao proces,ustanovljen i sprovođen od strane upravnog odbora preduzeća,menadžmenta i ostalog osoblja,a cilj mu je da obezbedi razumno uverenje vezano za postizanje ciljeva u sledećim kategorijama:Efikasnost i uspešnost poslovanja,pouzdanost finansijskog izveštavanja,saglasnost sa postojećim propisima i zakonima,zaštita imovine od neovlašćenog prisvajanja,korišćenja i otuđenja.

Navedena definicija interne kontpole održava sledeće osnovne koncepte i to: ${ }^{8}$

- Interna kontrola je proces.

- Internu kontrolu obavljaju ljudi neke organizacije.

- Od interne kontrole se očekuje da upravnom odboru i menadžmentu preduzeća pruži samo razumno uverenje, a ne apsolutno uverenje da su ciljevi organizacije ostvareni.

- Interna kontrola se primenjuje radi postizanja ciljeva u jednoj ili više kategorija koje su međusobno preklapaju.

- Zaštita imovine od preteranog trošenja,neefikasne upotrebe i mogućih prevara.

- Obezbeđenje pouzdanosti računovodstvenih podataka.

- Doslovna realizacija poslovne politike u svim delovima privrednog društva.

Sistem interne kontrole sastoji se od svih mera i metoda koje se primenjuju u preduzeću u cilju obezbeđenja njegovih sredstava od rasipanja,pronevera i neefikasnosti,unapređenje tačnosti i

\footnotetext{
${ }^{6}$ Master studije Javne finansije, Vojna akademija, Beograd, simijonovic s@gmail.com

7 Prema :,,ISO 400"

${ }^{8}$ Podela preuzeta sa sajta:,, http://www.scribd.com/doc/47299805/592-Interna-kontrola-Interni-nadzor"
} 
pouzdanosti knjihovodsvenih i operativnih podataka,pridržavanje poslovne politike preduzeća i ocene poslovne efikasnosti.(Martić, 2009)

Primarni cilj interne kontrole jeste da obezbedi: 9

- pouzdanost i integritet podataka;

- poštovanje politika, planova, procedura, zakona i propisa;

- čuvanje sredstava;

- ekonomično, efikasno i efektivno korišćenje resursa.

Svaka organizacija treba da osmisli sopstveni sistem interne kontrole sa ciljem da se zadovolje potrebe i okruženje organizacije.Opšta svrha interne kontrole jeste da organizaciji pomogne u ostvarivanju svoje misije (ciljeva Uspešan sistem interne kontrole pomaže u racionalizovanju procesa i unapređuje nivo i kvalitet usluga.Pruža razumno uveravanje da će se ostvariti opšti ciljevi.Interna kontrola treba da poveća verovatnoću da će se otkriti pronevere, umanjiti šteta, zloupotreba ili greške, sprečiti neadekvatne aktivnosti, odnosno poboljšati poštovanje propisa.Interna kontrola je odgovornost svih zaposlenih i svako ministarstvo treba da se pobrine da sistemi interne kontrole budu integrisani u aktivnosti. Zaposleni treba da budu obučeni u metodologiji i konceptima koji se odnose na sistem interne kontrole.

Interna kontrola sastoji se od pet međusobno povezanih komponenti:

- Kontrolno okruženje

- Pocena rizika

- Kontrolne aktivnosti

- Informacije i komunikacije

- Nadgledanje i praćenje

Kontrolno okruženje utvrđuje „ton“ u organizaciji i utiče na svest zaposlenih o kontrolama. strukturu.

Predstavlja osnovu za sve druge komponente interne kontrole, obezbeđujući disciplinu i

Faktori kontrolnog okruženja uključuju integritet, etičke vrednosti i stručnost zaposlenih u organizaciji, filozofiju i stil rada rukovodstva, način na koji rukovodstvo dodeljuje ovlašćenja i odgovornosti, i organizuje i unapređuje kadar, kao i pažnju i uputstva ministra.

Ovo je ranije pomenuto u drugoj temi kada smo govorili o utvrđivanju „tona“ i potrebi za jasnim smernicama najvišeg rukovodstva.

Organizacija mora da bude svesna rizika sa kojima se suočava i mora onjima da vodi računa.Poslovne ciljeve koje nastoji da ostvari,kompanija određuje,a uprava tih rizika.

Utvrđuje rizike vezane za postizanje zacrtanih ciljeva i preduzima određene korake radi kontrole

Da bi se upravi organizacije pomoglo da obezbedi realizaciju onih aktivnosti koje ona smatra neophodnim za kontrolisanje rizika vezanih za postizanje zacrtanih ciljeva preduzeća,moraju se ustanoviti i obavljati kontrole politike i procedure.One obuhvataju niz aktivnosti.lako su mnogobrojne,kontrolne aktivnosti se mogu svrstati u pet kategorija:

- Adekvatno razdvajanje dužnosti

- Pravilno odobravanje transakcija i aktivnosti

- Adekvatna dokumentacija i evidencija

- Fizička kontrola sredstava i poslovnih knjiga

- Nezavisne provere uspešnosti rada

$\mathrm{Na}$ svim nivoima organizacije potrebne su informacije:finansijske informacije,poslovne informacije,informacije 0 usklađenosti i informacije 0 spoljašnjim događajima,aktivnostima i uslovima.Pomenute informacije moraju da budu utvrđene,dobijene i prenete u onoj formi i vremenskom okviru koji će korisnicima omogućiti da obave svoje dužnosti i obaveze.Najvažniji sistem za internu kontrolu je računovodstveni sistem,koji se smatra serijom zadataka i knjiženja jednog preduzeća pomoću kojih se transakcije obrađuju radi vođenja finansijskih evidencija.

Celokupan proces mora da bude praćen i po potrebi se mora modifikovati.To se postiže konstantnim aktivnostima praćenja i nadgledanja,posebnim procenama ili kombinovanjem ta dva postupka.Sa analitičke tačke gledanja interna kontrola se može podeliti na dve široke kategorije nadzornog delovanja i to:administrativnu kontrolu i računovodstvenu kontrolu. Neophodno je pratiti sisteme interne kontrole - proces kroz koji se ocenjuje kvalitet funkcionisanja sistema tokom određenog perioda.

Ovo se postiže stalnim nadzornim aktivnostima, posebnim ocenama ili kombinacijom ova dva načina. Stalni nadzor se obavlja tokom samih poslova i podrazumeva redovne aktivnosti rukovodstva i nadzorne aktivnosti, kao i druge mere koje zaposleni preduzimaju tokom obavljanja svojih dužnosti.

\footnotetext{
${ }^{9}$ Podela preuzeta sa sajta na engleskom:,, http://www.k-state.edu/internalaudit/intcontr.html”
} 
Obim i učestalost posebnih ocena prvenstveno zavise od rizika i efektivnosti tekućih (stalnih) nadzornih aktivnosti. O slabostima interne kontrole treba izveštavati nadređene, a ozbiljna pitanja treba da budu predočena najvišem rukovodstvu i odboru.

Upravo ovde interna revizija igra važnu ulogu. Interna revizija obavlja revizije procesa i sistema koji su identifikovani kao prioritetni na osnovu procene rizika.

\section{LIMITIRANOST INTERNE KONTROLE U SPREČAVANJU PRONEVERA}

Značajnu prepreku za obavljanje prevara i pronevera predstavlja snažna i dobro organizovana interna kontrola,koja ipak nije u stanju da ih u potpunosti spreči.Mogućnost da dođe do pronevere je prisutna čak i u slučaju da organizacija ima adekvatan sistem interne kontrole i ako se svake godine podvrgava eksternoj finansijskoj reviziji.Razlog za navedeno leži u činjenici što je obum interne kontrole,koju preduzeća mogu da primenjuju,u velikoj meri ograničen njenim troškovima.

Sistem interne kontrole, bez obzira koliko je dobro osmišljen i dobro funkcioniše, može da pružu uveravanje samo u razumnoj meri, a ne apsolutno uveravanje rukovodstvu da će se ostvariti ciljevi organizacije. Verovatnoća ostvarivanja ciljeva zavisi od ograničenja koja su svojstvena svim sistemima interne kontrole. $U$ ova ograničenja spada i mogućnost da su sudovi (procene) u donošenju određenih odluka pogrešni, te da se nefunkcionisanje može dogoditi i usled najmanje greške ili propusta.

Pored toga, moguće je da se kontrole zaobiđu ukoliko se dva ili više lica udruže, a i samo rukovodstvo ima mogućnost da prenebregne sistem. Drugi ograničavajući faktor predstavlja činjenica da "dizajn" sistema interne kontrole mora da uzme u obzir ograničenja u pogledu resursa, te da se korist od kontrola mora razmatrati u odnosu na troškove tih kontrola.

$\mathrm{Ni}$ jedna struktura interne kontrole, bez obzira koliko je detaljna i sveobuhvatna, ne može sama po sebi da garantuje efikasno upravljanje i potpunu i tačnu evidenciju, niti može da bude „neprobojna“ za pronevere, naročito kad su u njih umešana lica na položajima koji nose određena ovlašćenja ili poverenje. Interne kontrole zasnovane na podeli dužnosti takođe mogu biti neefektivne u slučaju kad se udruži više lice.

Pored toga, kontrole vezane za overavanja/ovlašćenja takođe može zloupotrebiti lice kome je to ovlašćenje/overavanje povereno, a samo rukovodstvo često je u poziciji da prenebregne kontrole koje je uspostavilo.

Nije realno očekivati da se može održati struktura interne kontrole koja će eliminisati rizik od gubitaka, $i$ to bi verovatno koštalo više od same koristi koja bi se time dobila.

Budući da svaka struktura interne kontrole zavisi od ljudskog faktora, znači da je podložna manjkavostima u smislu dizajna, greškama u prosuđivanju ili tumačenju, nerazumevanju, nemaru, umoru ili rasejanosti.

lako je moguće kontrolisati kompetentnost i integritet lica koje radi na osmišljavanju i sprovođenju sistema putem selekcije i obuka, ovi kvaliteti mogu se promeniti i usled internog ili eksternog pritiska.

Uz to, bez obzira koliko su kompetentni zaposleni, kontrole koje oni sprovode mogu postati neefektivne ukoliko zaposleni na pravi način ne shvataju svoju funkciju u procesu kontrole, odnosno ignorišu je.

Promene u organizaciji i stav rukovodstva mogu imati snažan uticaj na efektivnost strukture interne kontrole i zaposlene koji sprovode tu strukturu.

Prema tome, rukovodstvo treba konstantno da revidira i ažurira kontrole, da predočava promene zaposlenima, te da drugima bude uzor u poštovanju tih kontrola.

\section{INTERNA FINANSIJSKA KONTROLA U JAVNOM SEKTORU}

Interna finansijska kontrola u javnom sektoru (Public Internal Financial Control - PIFC) je termin i koncept $^{10}$ sa ciljem da pruži pomoć u razumevanju i primeni dobro razvijenih i efektivnih sistema interne kontrole u procesu pridruživanja EU.

$P$ - Public Sector - javni sektor;

I - Internal to the organisation - interna za organizaciju;

F - Financial systems mainly but not exclusively - uglavnom, ali ne isključivo finansijski sistemi;

C - Control based on internationally accepted and recognised standards - kontrola zasnovana na međunarodno prihvaćenim i priznatim standardima.

Cilj kontrole jeste da obezbedi dobro upravljanje i ekonomičnu kontrolu javnih sredstava, pružajući poreskim obveznicima „vrednost“ za novac.Kontrola obuhvata sve sisteme i procedure interne kontrole u javnim institucijam, i oko njih, i pomaže u pružanju razumne uverenosti da se javna sredstva troše na odgovarajući način, te da se kroz njih ostvaruje vrednost.

\footnotetext{
${ }^{10}$ Razvijen od strane Evropske komisije
} 
Interna finansijska kontrola je opšti sistem finansijske kontrole koji interno sprovodi vlada, odnosno njene organizacije, sa ciljem da se obezbedi da finansijsko upravljanje i kontrola njenih budžetskih centara (uključujući i strane fondove) budu u skladu sa relevantnim propisima, opisom budžeta, i principima dobrog finansijskog upravljanja, transparetnosti, efikasnosti, efektivnosti i ekonomičnosti.Interna finansijska kontrola u javnom sektoru obuhvata sve mere kroz koje se kontrolišu državni prihodi, rashodi, sredstva i obaveze i predstavlja internu kontrolu u širem smislu. Uključuje, ali nije ograničena na finansijsku kontrolu i internu reviziju.

Model interne finansijske kontrole $\mathrm{u}$ javnom sektoru $=$ finansijsko upravljanje $\mathrm{i}$ kontrola + interna revizija + centralna jedinica za harmonizaciju

Postoje 3 elementa interne finansijske kontrole $u$ javnom sektoru koji funkcionišu zajedno $u$ ostvarivanju razumne uverenosti da interne kontrole funkcionišu adekvatno i efikasno:

- Finansijsko upravljanje i kontrola - i potreba za odgovornošću rukovodilaca za proces interne kontrole;

- Interna revizija - funkcionalno nezavisna i decentralizovana interna revizija koja vrši pregled efektivnosti itnernih kontrola;

- Centralna jedinica za harmonizaciju - posebna sekcija koja razrađuje i usmerava proces interne finansijske kontrole $u$ javnom sektoru.

\section{PERSPEKTIVE UVOĐENJA INTERNE REVIZIJE}

Interna revizija predstavlja naknadnu kontrolu poslovnih transakcija uključujući i kontrolu kontrole.Tamo gde je interna revizija instalirana,ona testira i ocenjuje računovodstvene i administrativne kontrole u svim sektorima.Zakon o preduzećima,međutim internu reviziju predviđasamo kao mogućnost,a ne kao obavezu.Kada govorimo o internoj reviziji,mislimo na profesionalno internu reviziju čiji je rad utemeljen na verifikovanim i opšteprihvaćenim standardima.S obzirom na činjenicu da je adekvatnog kadra u internoj reviziji danas veoma malo,to podrazumeva timski rad i angažovanje kadra koji nastoji da u internoj reviziji ostvari značajnu karijeru,kao i njegovo školovanje za internu reviziju.Interna revizija se obično organizuje u matičnim preduzećima,sa takvim ovlašćenjima da poslove može obavljati u matičnom i povezanim preduzećima,što omogućava usklađenost postupaka interne kontrole i veću efikasnost na svim nivoima.Na stvaranje osnove za internu reviziju pozitivno će se odraziti razvoj računovodstvene profesije.Do uvođenja interne revizije najpre će doći u onim preduzećima i bankama u koje bude uložen inostrani kapital,jer će inostrani investitori zahtevati primenu metodologije interne revizije,što će omogućiti i formiranje osnove za obrazovanje kadra i šire uvođenje interne revizije u našu praksu.Politika preduzeća jeste da uvede i ocenjuje poslovanja preduzeća radi pružanja pomoći menadžmentu preduzeća u realizaciji ciljeva definisanih poslovnom politikom preduzeća.Deo za internu reviziju je organizaciono vezan za generalnog menadžera,a svoje izveštaje podnosi generalnom menadžeru i upravnom i nadzornom odboru.Zaposleni u odeljenju za internu reviziju imaju pravo na potpun i slobodan pristup svim informacijama i dokumentaciji,radi obavljanja svojih poslova.Osnovni cilj organizacionog dela za internu reviziju jeste da na efikasan način pruži pomoć menadžmentu preduzeća u izvršavanju zadataka.Rukovodilac interne revizije,rukovodi internom revizijom u sektoru preduzeća,zavisnom preduzeću ili u drugom organizacionom delu i izvšava program interne revizije u skladu sa standardima revizije i uputstvima za rad i uspostavlja saradnju sa nadležnim rukovodiocima u organizacionim delovima u kojima se vrši revizija.

Interni revizor ima sledeće dužnosti: ${ }^{11}$

- Ispituje poslovanje preduzeća u oblasti koju je po programu dobio i ocenjuje adekvatnost i efikasnost internih kontrola u toj oblasti.

- Utvrđuje da li se u organizacionom delu u kom vrši reviziju primenjuju propisani postupci koji se odnose na planiranje,računovodstveno obuhvatanje,očuvanje sredstava preduzeća,kontrolu rada i da li su ti postupci usklađeni sa poslovnom politikom preduzeća i savremenim standardima organizacije poslovanja.

- Planira i izvodi reviziju u skladu sa profesionalnim standardima.

- Određuje nalaze revizije i preporuke za otklanjanje uočenih slabosti.

- Vrši specijalne preglede na zahtev računovodstva.

- Daje instrukcije mlađim revizorima.

$\mathrm{Na}$ organizaciju i efikasnost nadzora utiče veličina preduzeća.Komplikovanije je usavršiti internu kontrolu u malom nego u velikom preduzeću,iz jednostavnog razloga što na primer u malom preduzeću na sedam zaposlenih nije moguće urediti zadovoljavajuće razgraničenje ovlašćenja.Pored navedenog ima to i veze sa troškovima.Zaključak koj se može izvesti jeste da se struktura internog nadzora mora adaptirati individualnim potrebama svakog preduzeća ponaosob.Interna kontrola ima primarni cilj da preventivno deluje na suzbijanje prevara,koje se definišu kao namerno pogrešne interpretacije činjenica

\footnotetext{
${ }^{11}$ Podela je preuzeta sa sajta na enleskom:,, http://en.wikipedia.org/wiki/Internal_control"
} 
sa ciljem obmanjivanja i dovođenja u zabludu treće osobe.U slučaju kada računovodstveni nadzor otkrije nepravilnosti,tretira ih kao namerne greške unesene u računovodstvene evidencije,poslovne knjige i finansijske izveštaje u prevarantske svrhe.Nepravilnosti se mogu definisati u dve grupe i to:prevare koje su učinili zaposleni i prevare koje je učinio menadžment.Smanjenje rizika od prevare,falsifikata i drugih nečasnih radnji zaposlenih,u dobroj meri bi usledilo raspodelom ovlašćenja nad transakcijama.Terminom,,vezivanje vernosti" označave se osiguranje ovog neobičnog rizika,vrstom ugovora kojim se osiguravajuća firma obavezuje da isplati poslodavca na račun štete koja je nastala prevarom zaposlenih vezanih vernošću.U iskazivanju profitabilnosti preduzeća u obzir treba da se uzmu svi troškovi.Menadžment i upravni odbor su odgovorni za kontrolisanje ukupnih troškova,a samo uz stalni nadzor moguće je adekvatno upravljanje troškovima.

\section{ZAKLJUČAK}

$\mathrm{U}$ radu su pokrenuta su pitanja finansijskog upravljanja i kontrole sa posebnim akcentom na internu kontrolu. U odnosu na glavnu pokrenutu temu, pokrenuta su i sledeća pitanja: Značaj interne kontrole za funkcionisanje organizacije; Problemi funkcionisanja interne kontrole; Zadaci prilikom izvršenja interne kontrole; Uslovi razvoja interne kontroleMožemo zaključiti da je interna kontrola neminovnost kvalitetnog i organizovanog funkcionisanja preduzeća ili bilo kog drugog složenijeg sistema uključujuči i sistem odbrane. Uporedo sa poteškoćama uvođenja interne kontrole javlja se i potreba za njenom implmentacijom zarad maksimizacije funkcionisanja organizacije i smanjenje svih nepotrebnih troškova.

\section{LITERATURA}

1. Babić V., Korporativno upravljanje u uslovima tranzicije, Ekonomski fakultet, Kragujevac, 2004.

2. Đorđević, D, Bešić H, C, Sajfert,N Z, Leksikon Menadžmenta, Agencija Matić, Beograd, 2006.

3. Martić S., Upravljanje poslovnim finansijama, Beograd, 2009

4. Tepšić R.: Poslovne finansije, Informator

5. http://www.wikipedia.org/

6. http://www.ucop.edu/ctlacct/under-ic.pdf

7. http://www.ecgi.org/codes/documents/kpmg_internal_control_practical_guide.pdf

8. http://www.aicpa.org/Publications/InternalControl/Pages/InternalControl.aspx

9. http://www.k-state.edu/internalaudit/intcontr.html"

\section{Abstract}

Due to the very dynamic changes in the markets, especially in the capital markets, equity holders and investors need is a reliable and independent opinion on the financial statements of companies that are the subject of their interest. In conditions that are characterized by a large heterogeneous unification of the financial statements, the management company is looking for a better way of establishing control of the company, which is a long and continuous process. Full support that it provides internal control and internal audit business.

Key words: management, internal control, internal audit.

Rad primljen: 17.12.2015.

Rad prihvaćen: 26.02.2016. 